\title{
Occupational exposures and 20-year incidence of COPD: the European Community Respiratory Health Survey
}

Theodore Lytras ${ }_{1,2}{ }^{1,2}$ Manolis Kogevinas, ${ }^{1,2,3,4}$ Hans Kromhout, ${ }^{5}$ Anne-Elie Carsin, ${ }^{1,2}$ Josep M Antó, ${ }^{1,2,3,4}$ Hayat Bentouhami, ${ }^{6}$ Joost Weyler, ${ }^{6,7}$ Joachim Heinrich, ${ }^{8}$ Dennis Nowak, ${ }^{8}$ Isabel Urrutia, ${ }^{9}$ Jesús Martinez-Moratalla, ${ }^{10,11}$ José Antonio Gullón, ${ }^{12}$ Antonio Pereira-Vega, ${ }_{1}^{13}$ Chantal Raherison-Semjen, ${ }_{1}^{14}$ Isabelle Pin, ${ }_{1}^{15,16,17}$ Pascal Demoly, ${ }^{18,19}$ Bénédicte Leynaert, ${ }^{20}$ Simona Villani, ${ }^{21}$ Thorarinn Gislason, ${ }^{22,23}$ Cecilie Svanes, ${ }^{24,25}$ Mathias Holm, ${ }^{26}$ Bertil Forsberg, ${ }^{27}$ Dan Norbäck, ${ }_{1}^{28}$ Amar J Mehta, ${ }^{29}$ Nicole Probst-Hensch, ${ }^{30,31}$ Geza Benke, ${ }^{32}$ Rain Jogi, ${ }^{33}$ Kjell Torén, ${ }^{34}$ Torben Sigsgaard, ${ }^{35}$ Vivi Schlünssen, ${ }^{35,36}$ Mario Olivieri, ${ }^{37}$ Paul D Blanc, ${ }^{38}$ Roel Vermeulen, ${ }^{5}$ Judith Garcia-Aymerich, 1,2,3,4 Deborah Jarvis, ${ }^{39,40}$ Jan-Paul Zock ${ }^{1,2,3}$

- Additional material is published online only. To view please visit the journal online (http://dx.doi.org/10.1136/ thoraxinl-2017-211158).

For numbered affiliations see end of article.

\section{Correspondence to}

Dr Theodore Lytras, Barcelona Institute of Global Health (ISGlobal), Barcelona 08003, Spain; thlytras@gmail.com

Received 13 October 2017 Revised 16 February 2018 Accepted 26 February 2018 Published Online First 24 March 2018

\section{Linked}

- http://dx.doi.org/10.1136/ thoraxjnl-2018-211661

Check for updates

To cite: Lytras T,

Kogevinas M, Kromhout $\mathrm{H}$, et al. Thorax

2018:73:1008-1015.

\section{ABSTRACT \\ Background Occupational exposures have been} associated with an increased risk of COPD. However, few studies have related objectively assessed occupational exposures to prospectively assessed incidence of COPD, using postbronchodilator lung function tests. Our objective was to examine the effect of occupational exposures on COPD incidence in the European Community Respiratory Health Survey.

Methods General population samples aged 20-44 were randomly selected in 1991-1993 and followed up 20 years later (2010-2012). Spirometry was performed at baseline and at follow-up, with incident COPD defined using a lower limit of normal criterion for postbronchodilator FEV1/FVC. Only participants without COPD and without current asthma at baseline were included. Coded job histories during follow-up were linked to a Job-Exposure Matrix, generating occupational exposure estimates to 12 categories of agents. Their association with COPD incidence was examined in logbinomial models fitted in a Bayesian framework.

Findings 3343 participants fulfilled the inclusion criteria; 89 of them had COPD at follow-up (1.4 cases/1000 person-years). Participants exposed to biological dust had a higher incidence of COPD compared with those unexposed (relative risk (RR) 1.6, $95 \% \mathrm{Cl} 1.1$ to 2.3 ), as did those exposed to gases and fumes (RR 1.5, 95\% Cl 1.0 to 2.2) and pesticides (RR 2.2, 95\% Cl 1.1 to 3.8). The combined population attributable fraction for these exposures was $21.0 \%$. Interpretation These results substantially strengthen the evidence base for occupational exposures as an important risk factor for COPD.

\section{INTRODUCTION}

COPD is a progressive respiratory disease characterised by a largely non-reversible obstruction of the airways leading to airflow limitation. ${ }^{1}$ It is a leading cause of morbidity and mortality worldwide, whose

\section{Key messages}

What is the key question?

- What is the effect of occupational exposures on postbronchodilator spirometry-defined COPD incidence?

What is the bottom line?

- Exposure to biological dusts, gases and fumes, and pesticides were associated with increased COPD incidence, and together accounted for $21 \%$ of cases in the study population.

Why read on?

- This is the first multicentre prospective study to show an effect of biological dusts and of pesticides on COPD incidence, substantially strengthening the evidence base for occupation as a risk factor for COPD.

impact is expected to further increase as the population ages. ${ }^{2-4}$ Tobacco smoking is the primary risk factor for $\mathrm{COPD}^{5}$; however, many other environmental factors have been implicated in COPD, including occupational exposures. ${ }^{6} 7$ Numerous studies, both population-based and industry-based, have examined the relationship between occupation and COPD-related outcomes. ${ }^{6-11}$ An interaction between smoking and occupational exposures has also been observed. ${ }^{12}$ It has been estimated that about $15 \%$ of COPD cases are attributable to exposures at the workplace, ${ }^{8}$ with a higher population attributable fraction among non-smokers. ${ }^{13} 14$

Despite a wealth of evidence on COPD risk factors from population-based studies, few such studies have assessed the incidence of COPD in a prospective manner, ${ }^{15} 16$ and even fewer have specifically examined the association between occupational exposures and the incidence of spirometry-defined COPD. ${ }^{17}$ The discussion about 
occupational exposures and COPD is very old, particularly with exposures such as gases and dusts. ${ }^{18} 19$ However, in recent decades, entire industries and occupations have changed, transformed or outright disappeared, and protective measures have been implemented in many cases. At the same time, there is a worldwide decline in the prevalence of smoking, ${ }^{20}$ which the leading risk factor for COPD and is related to occupation and socioeconomic status. ${ }^{21}$ In this new context, the association of occupational exposures with COPD incidence requires re-examination, as results from older studies might not still be applicable today.

The European Community Respiratory Health Survey (ECRHS) is a large multicentre population-based longitudinal study with a long follow-up duration; earlier cross-sectional and longitudinal analyses in this relatively young cohort showed an association between occupation and asthma as well as chronic bronchitis symptoms, but not with accelerated lung function decline or increased COPD incidence. ${ }^{22} 23$ The objective of the current analysis was to examine the effect of occupational exposures on postbronchodilator spirometry-defined COPD incidence in the ECRHS, after 20 years of follow-up.

\section{METHODS}

\section{ECRHS study overview}

The ECRHS is a multicentre longitudinal study initiated in 1991-1993, which enrolled random general population samples aged 20 to 44 years in 55 centres from 23 countries. ${ }^{24}$ Participants at baseline (ECRHS I) completed a detailed questionnaire via face-to-face interview and underwent a clinical examination, spirometry and other tests. They were followed up again between 1998 and 2002 (ECRHS II), and a second time between 2010 and 2012 (ECRHS III). Ethical approval for each centre was obtained from their respective competent bodies, and written informed consent was obtained from all participants.

\section{Study population, spirometry and COPD definition}

The population eligible for this study included all participants who completed spirometry at baseline (ECRHS I) and at the second follow-up (ECRHS III). Spirometry was performed according to the American Thoracic Society/European Respiratory Society standards for reproducibility, using the maximum value observed per participant for the FVC and FEV1. Baseline spirometry at ECRHS I was performed without bronchodilation; spirometry at ECRHS III was performed postbronchodilation, 15 min after administering two $100 \mu \mathrm{g}$ puffs of salbutamol using a spacer. We excluded participants with a baseline FEV1/ FVC ratio under the lower limit of normal (LLN) for their age, sex and gender according to the GLI-2012 equations. ${ }^{25}$ We also excluded participants who reported having current asthma at baseline; current asthma was defined as a positive response to either of the following three questions: "have you had an attack of asthma in the last 12 months?", "are you currently taking any medicines for asthma?" and "have you been woken by an attack of shortness of breath at any time in the last 12 months?". Incident COPD was defined using spirometry only, as a postbronchodilator FEV1/FVC ratio under the LLN at the end of follow-up.

\section{Occupational exposure assessment}

At both follow-up interviews, participants were asked to provide a detailed list of their occupations and industries from jobs held since the previous study visit that were performed for at least 8 hours a week for at least 3 months. Each such employment was recorded in free text and subsequently coded in the International Classification of Occupations-88 (ISCO-88) by trained local coders. Occupations were also further grouped into 14 wider job categories, as previously defined. ${ }^{23}$ Occupational exposures were assessed by linking the ISCO-88 occupational codes to the semiquantitative ALOHA(+) Job-Exposure Matrix (JEM). ${ }^{26}$ This JEM assigns, for every job code, three grades of exposure (none, low, high) to 10 categories of agents (biological dusts, mineral dusts, gases/fumes, herbicides, insecticides, fungicides, aromatic solvents, chlorinated solvents, other solvents and metals) plus two composites of the above (all pesticides and vapours/gases/dusts/fumes-VGDF). Exposures for every participant were defined and analysed for the entire follow-up period, that is, from ECRHS I to ECRHS III.

\section{Data analysis}

Log-binomial regression models were used to estimate the probability of COPD at the end of follow-up period as a function of exposure, covariates and length of follow-up; these models directly provide relative risk estimates for each covariate. Given that the incidence of COPD is heavily associated with lung function at baseline, ${ }^{27}$ we further adjusted all models for participants' FEV1/FVC ratio at baseline, expressed as per cent predicted according to the GLI-2012 equations. Other covariates used for adjustment were age at baseline, sex, lifetime smoking packyears, socioeconomic status (SES) and early life disadvantage score. Early life disadvantage score is a composite variable that includes maternal smoking, maternal asthma, paternal asthma, childhood asthma (before age 10) and having a serious respiratory infection before age $5 .^{28}$ SES was defined according to the participants' age of completion of formal education and classified into three categories: high (>19 years), middle (16-19 years) and low ( $<16$ years). We also included quadratic terms for age at baseline and lifetime smoking pack-years in order to account for any non-linear relationships between these important covariates and COPD incidence. ${ }^{29}$

Each of the 12 ALOHA $(+)$ exposures was assessed in a univariate fashion, that is, exposed versus unexposed (to the respective agent). Given the substantial overlap between exposures in certain jobs, we also examined each one in comparison to a common group consisting of those unexposed to all 12 occupational agents under study. In addition, for certain exposures, we fit bivariate models, that is, models with two exposures, where the effect of each one is adjusted for the presence of the other. Stratified effects by sex were obtained by including appropriate interaction terms in the models, and dose-response was examined by including separate terms for only low and for ever high exposure. As a sensitivity analysis, we refitted the models after excluding incident asthma cases, that is, those reporting asthma (as defined above) in either of the two ECRHS follow-up visits. As a further sensitivity analysis, we also fitted 'reduced' models without adjustment for SES, early life disadvantage score and baseline FEV1/FVC. A secondary analysis involved using job categories as the exposure, that is, ever working in a particular category during follow-up, in comparison to a common unexposed group consistently working in white-collar occupations.

All models were fitted in a Bayesian framework with the JAGS software,$^{30}$ setting non-informative Gaussian priors for all fixed-effects parameters, and using 4 chains and 32000 iterations per chain, discarding the first 2000 as burn-in. Convergence was checked by visual inspection of the MCMC traceplots and by the Gelman-Rubin statistic. The Bayesian framework avoids convergence issues that have sometimes been reported when fitting log-binomial models in 


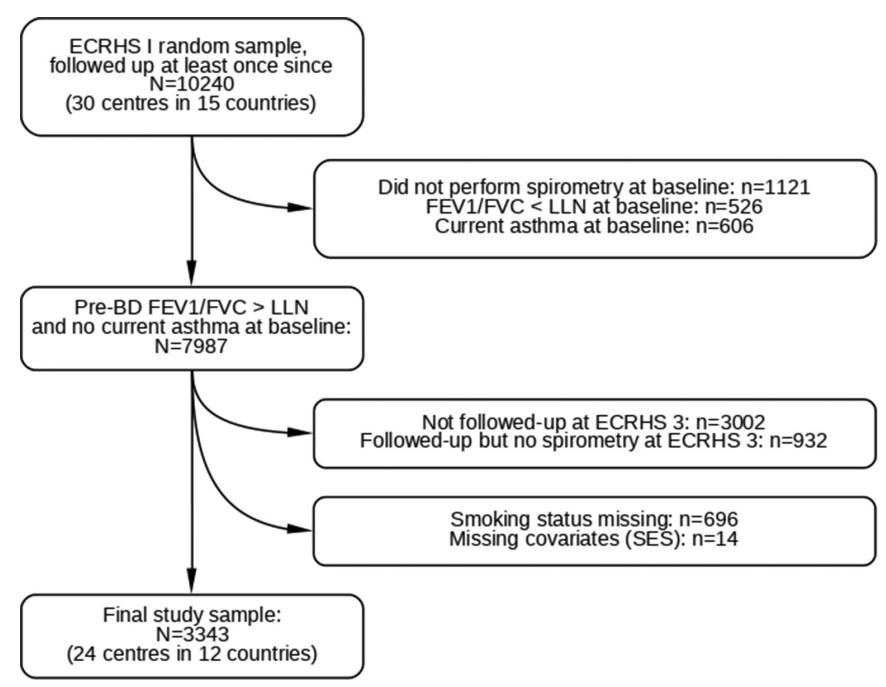

Figure 1 Flow chart of the European Community Respiratory Health Survey (ECRHS) participants into the study population, and reasons for exclusion. LLN, lower limit of normal; SES, socioeconomic status.

a frequentist setting. To address covariate missingness with respect to lifetime smoking pack-years (for current and ex-smokers), a fully Bayesian imputation submodel was included where the distribution of pack-years was modelled with a Gamma distribution based on the observed cases, under an ignorable missingness assumption (see online supplement).

Based on the relative risk estimates, population attributable fractions (PAFs) were calculated both for individual exposures and combinations of exposures (see online supplement). ${ }^{31}$ All analyses were performed with the R statistical environment, V.3.4.1. ${ }^{32}$

\section{Role of the funding source}

No sponsor of the study had a role in study design, data collection, data analysis, data interpretation or writing of the report. The corresponding author had full access to all the data in the study and had final responsibility for the decision to submit for publication.

\section{RESULTS}

The flow of ECRHS participants into our study sample is illustrated in figure 1; in total, 3343 participants were analysed, originating from 24 study centres in 12 countries (Australia, Belgium, Estonia, France, Germany, Iceland, Italy, Norway, Spain, Sweden, Switzerland and UK). Of these participants, 1409 were never smokers and 1934 were ever smokers (current or ex-smokers at the end of follow-up). The characteristics of our study population are shown on table 1 . Median age at baseline was 34.5 years, and the mean duration of follow-up was 20.0 years (range 18.0-22.4). COPD occurred in 96 participants, for an incidence of 1.4 cases/1000 person-years. As expected, COPD incidence in ever smokers was much higher than in never smokers $(2.0$ vs 0.6 cases $/ 1000$ person-years, $\mathrm{P}<0.001)$. Lifetime smoking pack-years at follow-up were missing in 448/1934 ever smokers (23.2\%, or $13.4 \%$ of the entire study population), for whom Bayesian imputation was performed.

Baseline characteristics were generally similar between the 3343 participants included in the analysis and the 4644 who were eligible (FEV1/FVC>LLN and no current asthma at baseline) but could not be included; those not included in the analysis were slightly more likely to be ever smokers and of lower SES than those finally analysed (see online supplementary table 1).

The percentage of participants exposed ranged across the occupational agents, from a minimum of $4.9 \%$ to pesticides

\begin{tabular}{|c|c|c|c|c|c|}
\hline & Total & Ever smokers & Never smokers & Men & Women \\
\hline No of participants & 3343 & 1934 & 1409 & 1638 & 1705 \\
\hline Person-years of follow-up & 66854 & 38648 & 28207 & 32709 & 34145 \\
\hline Mean follow-up and range (years) & $20.0(18.0-22.4)$ & $20.0(18.0-22.4)$ & $20.0(18.2-22.1)$ & $20.0(18.0-22.3)$ & $20.0(18.2-22.4)$ \\
\hline No of incident COPD cases & 96 & 79 & 17 & 51 & 45 \\
\hline COPD incidence per 1000 person-years & 1.4 & 2.0 & 0.6 & 1.6 & 1.3 \\
\hline$\%$ men & 49.0 & 51.7 & 45.4 & - & - \\
\hline Mean age at baseline (years) & 34.2 & 34.7 & 33.5 & 34.3 & 34.0 \\
\hline Mean lifetime pack-years of smoking at follow-up & 10.6 & 20.6 & - & 13.3 & 7.9 \\
\hline$\%$ current asthma at follow-up & 8.1 & 8.4 & 7.7 & 6.2 & 10.0 \\
\hline \multicolumn{6}{|l|}{$\%$ of participants exposed (low or high) } \\
\hline Biological dust & 32.3 & 32.5 & 32.0 & 30.0 & 34.4 \\
\hline Mineral dust & 25.2 & 28.1 & 21.2 & 36.7 & 14.1 \\
\hline Gases and fumes & 43.5 & 45.8 & 40.4 & 51.7 & 35.7 \\
\hline Vapours, gases, dusts and fumes & 48.4 & 50.1 & 46.1 & 56.4 & 40.7 \\
\hline Herbicides & 2.2 & 2.1 & 2.4 & 3.2 & 1.3 \\
\hline Insecticides & 3.4 & 3.5 & 3.3 & 4.9 & 1.9 \\
\hline Fungicides & 3.9 & 4.2 & 3.5 & 6.3 & 1.7 \\
\hline All pesticides & 4.9 & 5.4 & 4.3 & 7.7 & 2.2 \\
\hline Aromatic solvents & 16.4 & 17.1 & 15.4 & 26.7 & 6.4 \\
\hline Chlorinated solvents & 13.1 & 14.2 & 11.7 & 21.1 & 5.5 \\
\hline Other solvents & 28.5 & 27.8 & 29.4 & 32.1 & 25.0 \\
\hline Metals & 12.6 & 13.6 & 11.2 & 22.9 & 2.7 \\
\hline
\end{tabular}




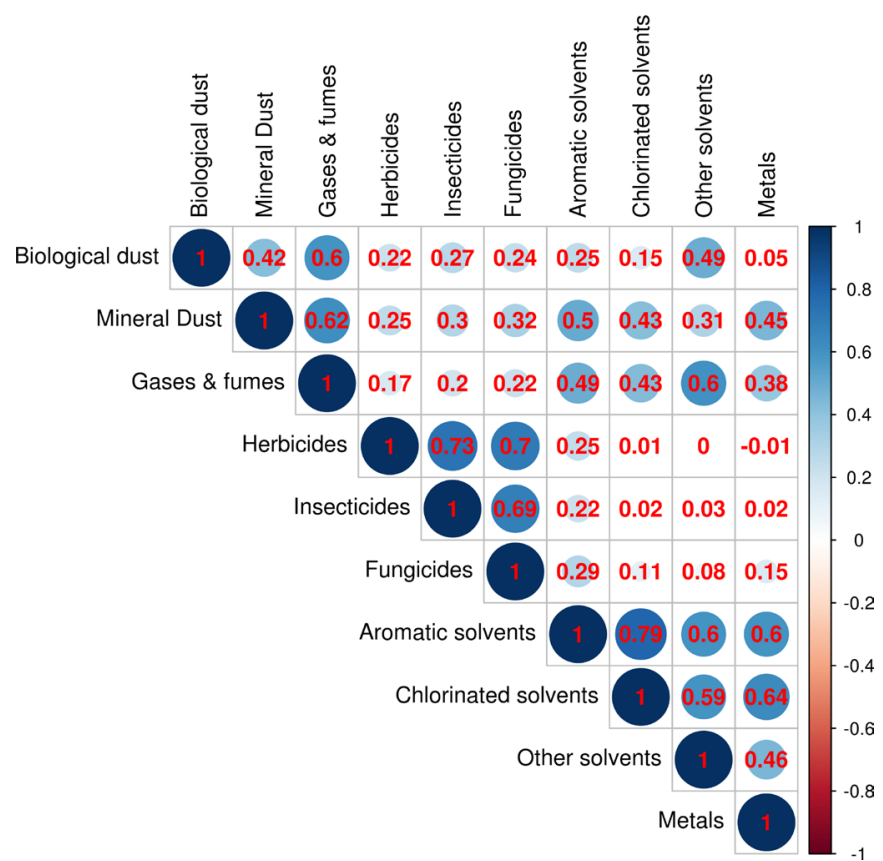

Figure 2 Correlation map (Spearman's rho) between occupational exposures in the study population $(n=3343)$.

to a maximum of $48.4 \%$ to VGDF; 1696 participants $(50.7 \%)$ did not have any low or high occupational exposure during the follow-up period. There was substantial overlap and thus correlation between exposures (figure 2), particularly between the various types of pesticides and solvents, and also between gases and fumes and other exposures.

The effect (relative risk (RR) and 95\% Credible Intervals) of occupational exposures on COPD incidence compared with participants unexposed (to the respective agent) is presented in table 2. For all exposures except solvents and metals, the crude incidence of COPD among exposed (percentage of participants with COPD at the end of follow-up) was higher than among those unexposed. After adjusting for covariates in log-binomial models, there was a significant effect for biological dust (RR 1.6, $95 \%$ CI 1.1 to 2.3 vs unexposed) as well as for all pesticides (RR 2.2, 95\% CI 1.1 to 3.8), and in particular insecticides
(RR 2.3, 95\% CI 1.1 to 4.2); however, the effect for all pesticides and insecticides was based on a small number of cases (10 and 8, respectively). Gases and fumes showed a significant effect compared with participants with no such exposure (RR 1.5, 95\% CI 1.0-2.2), while for mineral dust and VGDF the effect was not significant.

Running the models after excluding incident asthma cases did not materially change the results (see online supplementary table 2 ); biological dust and gases and fumes showed a marginally stronger effect (RR 2.0, 95\% CI 1.2 to 3.1, and RR 1.9, 95\% CI 1.2 to 3.0 , respectively), while the effect for pesticides was the same (RR 1.9, 95\% CI 0.8 to 3.9). We also ran the models using a common, fully unexposed comparator group (see online supplementary table 3); this also did not substantially alter the results, although for gases and fumes the effect fell below the conventional level of statistical significance (RR 1.4, 95\% CI 1.0 to 2.1 ).

Including both any biological dust and any pesticide exposure in the same log-binomial model, mutually adjusting each effect for the presence of the other, resulted in a RR of $1.5,95 \% \mathrm{CI}$ 1.0 to 2.2 and $1.8,95 \%$ CI 0.9 to 3.2 for biological dust and pesticides, respectively. Adding also exposure to gases and fumes to this model resulted in increased uncertainty and an RR of 1.3, 95\% CI 0.8 to 2.2 for biological dust, $1.7,95 \%$ CI 0.9 to 3.2 for pesticides, and 1.2, 95\% CI 0.7 to 2.0 for gases and fumes. Assuming these point RRs and the proportions of exposed participants in our study population, the corresponding PAFs were $10.5 \%$ for biological dust, $4.4 \%$ for pesticides and $9.2 \%$ for gases and fumes; the combined $\mathrm{PAF}^{31}$ for all three exposures was $21.0 \%$.

No differences between men and women were observed in the effect of occupational exposures on the incidence of COPD (see online supplementary table 4). We also ran models for each exposure stratified by intensity, that is, no exposure versus any low versus any high exposure. In these models, there was weak evidence of a dose-response relationship for biological dust, but none for pesticides, gases and fumes or other exposures (table 3 ). The additional RR for high biological dust exposure compared with low exposure was $1.5,95 \%$ CI 0.8 to 2.8 , as there were few incident COPD cases particularly in the high exposure group $(10 / 111,9.0 \%)$.

Table 2 Associations between occupational exposures and COPD incidence

\begin{tabular}{|c|c|c|c|c|}
\hline & Cases in unexposed (\%) & Cases in exposed (\%) & Relative risk $(95 \% \mathrm{Cl})$ & Population attributable fraction (\%) \\
\hline Biological dust & $55 / 2264(2.4)$ & $41 / 1079(3.8)$ & 1.6 (1.1 to 2.3$)$ & 16.0 \\
\hline Mineral dust & $65 / 2501(2.6)$ & $31 / 842(3.7)$ & $1.1(0.7$ to 1.7$)$ & 3.9 \\
\hline Gases and fumes & $41 / 1888(2.2)$ & $55 / 1455(3.8)$ & 1.5 (1.0 to 2.2$)$ & 19.4 \\
\hline Vapours, gases, dusts and fumes & $40 / 1725(2.3)$ & $56 / 1618(3.5)$ & $1.3(0.9$ to 2.0$)$ & 14.1 \\
\hline Herbicides & $91 / 3269(2.8)$ & $5 / 74(6.8)$ & $2.0(0.7$ to 4.1$)$ & 2.6 \\
\hline Insecticides & $88 / 3229(2.7)$ & $8 / 114(7.0)$ & 2.3 (1.1 to 4.2$)$ & 4.7 \\
\hline Fungicides & $88 / 3211(2.7)$ & $8 / 132(6.1)$ & $1.9(0.9$ to 3.6$)$ & 3.9 \\
\hline All pesticides & $86 / 3179(2.7)$ & $10 / 164(6.1)$ & 2.2 (1.1 to 3.8$)$ & 5.6 \\
\hline Aromatic solvents & $80 / 2796(2.9)$ & $16 / 547(2.9)$ & $0.9(0.5$ to 1.5$)$ & - \\
\hline Chlorinated solvents & $83 / 2904(2.9)$ & $13 / 439(3.0)$ & $0.8(0.5$ to 1.4$)$ & - \\
\hline Other solvents & $71 / 2391(3.0)$ & 25/952 (2.6) & $0.8(0.5$ to 1.3$)$ & - \\
\hline Metals & $82 / 2922(2.8)$ & $14 / 421(3.3)$ & $1.0(0.5$ to 1.6$)$ & - \\
\hline
\end{tabular}

Separate models for ever low or ever high exposure to an agent compared with no exposure to that specific agent. $n=3343$ European Community Respiratory Health Survey participants from 24 study centres without COPD and without asthma at baseline.

Relative risks adjusted for sex, age, pack-years of smoking, FEV1/FVC ratio at baseline (\%predicted), socioeconomic status and early life disadvantage score. 
Table 3 Associations between occupational exposures and COPD incidence, stratified by intensity of exposure

\begin{tabular}{|c|c|c|c|c|c|}
\hline & Cases in unexposed (\%) & $\begin{array}{l}\text { Cases in ever } \\
\text { low-exposed (\%) }\end{array}$ & $\begin{array}{l}\text { Cases in ever } \\
\text { high-exposed (\%) }\end{array}$ & $\begin{array}{l}\text { Relative risk }(95 \% \mathrm{Cl}) \text {, } \\
\text { ever low vs no exposure }\end{array}$ & $\begin{array}{l}\text { Relative risk }(95 \% \mathrm{Cl}) \text {, } \\
\text { ever high vs no exposure }\end{array}$ \\
\hline Biological dust & $55 / 2264(2.4)$ & $31 / 905(3.4)$ & $10 / 174(5.7)$ & 1.5 (1.0 to 2.2$)$ & $2.2(1.2$ to 4.0$)$ \\
\hline Mineral dust & $65 / 2501(2.6)$ & $18 / 554(3.2)$ & $13 / 288(4.5)$ & $1.0(0.6$ to 1.7$)$ & 1.3 (0.7 to 2.2$)$ \\
\hline Gases and fumes & $41 / 1888(2.2)$ & 45/1102 (4.1) & 10/353 (2.8) & 1.6 (1.1 to 2.5$)$ & $1.0(0.5$ to 1.9$)$ \\
\hline $\begin{array}{l}\text { Vapours, gases, dusts } \\
\text { and fumes }\end{array}$ & 40/1725 (2.3) & 35/1067 (3.3) & 21/551 (3.8) & 1.3 (0.8 to 2.0$)$ & $1.3(0.8$ to 2.3$)$ \\
\hline Herbicides & $91 / 3269(2.8)$ & $1 / 49(2.0)$ & $4 / 25(16.0)$ & 0.5 (0.0 to 3.0$)$ & 2.8 (1.0 to 5.9$)$ \\
\hline Insecticides & $88 / 3229(2.7)$ & $3 / 54(5.6)$ & $5 / 60(8.3)$ & $2.0(0.5$ to 5.2$)$ & 2.2 (0.8 to 4.5$)$ \\
\hline Fungicides & $88 / 3211(2.7)$ & $4 / 72(5.6)$ & $4 / 60(6.7)$ & 1.5 (0.5 to 3.7$)$ & 2.0 (0.7 to 4.6$)$ \\
\hline All pesticides & $86 / 3179(2.7)$ & $5 / 94(5.3)$ & $5 / 70(7.1)$ & $2.0(0.7$ to 4.4$)$ & 2.1 (0.8 to 4.3 ) \\
\hline Aromatic solvents & 80/2796 (2.9) & $14 / 495(2.8)$ & 2/52 (3.8) & $0.8(0.5$ to 1.4$)$ & 1.3 (0.2 to 4.6$)$ \\
\hline Chlorinated solvents & 83/2904 (2.9) & $9 / 320(2.8)$ & $4 / 119(3.4)$ & $0.8(0.4$ to 1.6$)$ & 0.7 (0.2 to 1.7$)$ \\
\hline Other solvents & 71/2391 (3.0) & $22 / 883(2.5)$ & $3 / 69(4.3)$ & $0.8(0.5$ to 1.2$)$ & $1.4(0.4$ to 4.0$)$ \\
\hline Metals & $82 / 2922(2.8)$ & $10 / 287(3.5)$ & 4/134 (3.0) & $1.0(0.5$ to 1.9$)$ & $0.7(0.2$ to 1.7$)$ \\
\hline
\end{tabular}

Relative risks adjusted for sex, age, pack-years of smoking, FEV1/FVC ratio at baseline (\%predicted), socioeconomic status and early life disadvantage score.

Among covariates in the models, age and smoking pack-years were strongly associated with COPD, as expected. Men were only slightly more likely than women to suffer from COPD (adjusted RR 1.2, 95\% CI 0.8 to 1.7). Importantly, there was a strong inverse relationship between \%predicted FEV1/FVC at baseline and COPD incidence at the end of the follow-up period (figure 3); each percentage point of increase lowered the incidence of COPD by a factor (RR) of $0.8,95 \%$ CI 0.8 to 0.9 . Early life disadvantage score did not affect COPD incidence (RR per unit change $1.0,95 \%$ CI 0.8 to 1.3 ), and neither did medium (RR $0.9,95 \%$ CI 0.6 to 1.3 ) or low SES (RR $0.8,95 \%$ CI 0.4 to 1.5$)$.

Associations between occupational exposures and COPD incidence were not substantially modified by omitting adjustments for SES, early life disadvantage score and/or \%predicted FEV1/ FVC at baseline (see online supplementary table 5).

The secondary analysis by job category indicated a higher incidence of COPD in participants who had worked in the transport industry $(1.7,95 \%$ CI 0.9 to 3.2$)$, in the wood, paper and textile industry $(2.1,95 \%$ CI $0.9-4.5)$ and in agriculture, fishery and forestry $(2.3,95 \%$ CI 0.9 to 5.0$)$; however, the precision of

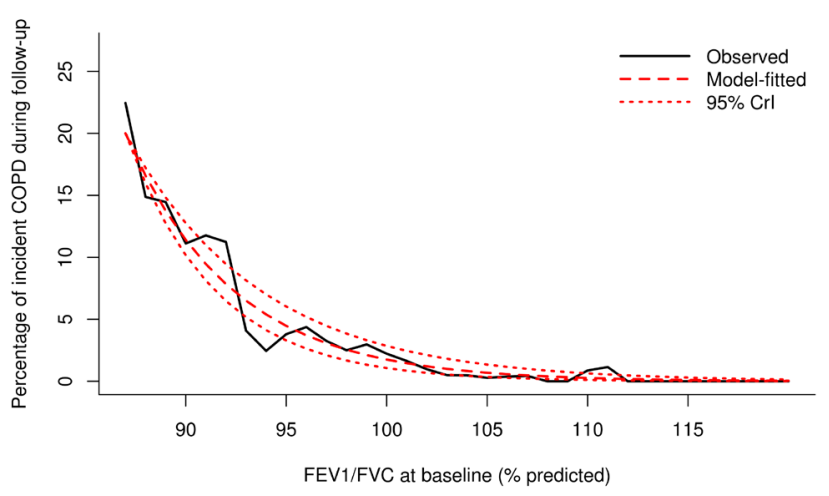

Figure 3 Percentage of incident COPD cases according to \%predicted FEV1/FVC at baseline, observed and model-fitted. For the observed cases, the percentage is calculated considering the participants with \%predicted FEV1/FVC \pm 1 percentage point. these estimates was limited by the low number of study participants working in each job category (see online supplementary table 6). Occupations belonging to these three categories were very frequently exposed to biological dust, pesticides and gases/ fumes. Overall, the most frequent occupations with exposure to these agents are shown in online supplementary table 7.

\section{DISCUSSION}

Our study found that exposure to biological dust in a general population cohort did result in an increased incidence of spirometrically defined COPD over the course of 20 years. Biological dust has been shown to affect lung function decline and chronic respiratory symptoms in several worker-based studies such as in farmers, cotton textile and woodworkers. ${ }^{33-36}$ An association with COPD prevalence has also been demonstrated in a community-based cross-sectional study ${ }^{26}$ and recently in another one from Australia. ${ }^{37}$ To our knowledge, this is the first study to demonstrate an effect of biological dust exposure on the incidence of COPD in a prospective fashion in a general population cohort. This effect remained strong even after adjustment for other exposures or exclusion of incident asthma cases, and also exhibited some evidence of a dose-response relationship, that is, a higher incidence of COPD with high exposure to biological dust. As such, the study is a significant addition to the evidence base about the role of biological dust on respiratory health.

Exposure to pesticides has also been linked with asthma and possibly COPD in a variety of studies. ${ }^{37-39}$ More recently, an association of pesticide exposure with accelerated lung function decline was observed in a longitudinal community-based study from the Netherlands; this association was stronger for smokers. ${ }^{40}$ Our study adds further prospective confirmation that pesticides increase the incidence of COPD. Interestingly, in our study, exposure to pesticides occurred in the 1990s and 2000s, while in the Dutch study, exposure happened mostly before 1990; this may indicate that contemporary changes in active ingredients, pesticide application methods and personal protective measures may have been insufficient to mitigate the risk to workers.

On the other hand, the lack of association between mineral dust exposure and COPD incidence may be explained by the composition of jobs included in this category (see online supplementary table 7). Older studies found a link between mining 
(especially coal mining), as well as various industrial occupations, and COPD. Such mining and industrial jobs were a minority in our study population, which was recruited in the early 1990s. Instead, the most frequent jobs with exposure to mineral dust in our study were truck and lorry drivers for men, and cleaners for women.

Disentangling the effects of multiple overlapping occupational exposures is a particular challenge. Our approach was twofold, that is, we compared each exposure with those unexposed, and separately with a common fully occupationally unexposed comparison group. The first choice of comparator is simpler, but includes other occupational exposures that may attenuate any association with the exposure under study. The second comparator (fully unexposed group) avoids this problem, but may increase the potential for residual confounding particularly with respect to SES, as the people in this group (mostly white-collar workers) are likely to be different in more ways than a model can handle. Nevertheless, in our case, we found similar results with both approaches. We then followed up with bivariate and multivariate models, that is, models that include more than one occupational exposure, as well as an analysis by job category; however, this requires a large sample size to maintain precision in the effect estimates.

Occupational exposures have been associated with both asthma and COPD incidence in population studies ${ }^{17}{ }^{41}$; COPD and asthma are two different disease entities, modulated by distinct pathophysiological mechanisms, but with considerable clinical and symptom overlap. ${ }^{42}$ As a result, in our basic analyses, we did not exclude incident asthma cases. A sensitivity analysis with incident asthma cases excluded did not substantially modify the results.

In all models, we adjusted for the FEV1/FVC ratio at baseline, expressed as \%predicted, which we found to be a strong predictor of subsequent COPD incidence. This is hardly surprising since COPD is not a stochastic event, but one that results from a progressive lung function decline below a given threshold. As such, the 'distance to be covered' between baseline FEV1/FVC and the LLN threshold is critical, and we believe it should be adjusted for in future prospective studies of COPD incidence.

The study has several strengths. Being a population-based study increases generalisability of the findings, especially given the prospective design and follow-up of 20 years, one of the longest to date. Complete occupational histories were collected, and a full spectrum of exposures for the follow-up period was determined using a JEM instead of self-report, which could be more vulnerable to bias. We were thus able to explore the effect of particular exposures on COPD incidence and their contribution to the disease burden. Confounders were tightly controlled: we included adjustments for SES and baseline lung function, and we accounted for non-linear relationships with age and smoking pack-years using quadratic terms; therefore, residual confounding by intensity of smoking is most unlikely. Lifetime pack-years of smoking were missing in many current or ex-smokers of our study population; we used fully Bayesian imputation to handle the problem and draw reliable inference while reflecting the appropriate uncertainty, assuming ignorable missingness (see online supplement).

On the other hand, COPD incidence in our study population was much lower than in other published studies ${ }^{15} 4344$; the most likely reason for this was the still fairly young age of our cohort at follow-up (median age 55, range 39-68 years). Also, the use of prebronchodilation spirometry at baseline to filter out prevalent COPD cases may have led to the exclusion of some participants with reversible or borderline obstruction at baseline. Because of the low number of incident COPD cases, especially in lifetime non-smokers, we could not stratify our analysis by smoking status to check for effect modification. For the same reason, several of our effect estimates were characterised by low precision, especially those stratified by sex and by intensity of exposure. In addition, we defined COPD with postbronchidilation spirometry only and not based on symptoms of chronic bronchitis, which would have raised specificity but severely limited the number of incident cases in this analysis. Another limitation stems from the fact that the outcome of COPD was only assessed at the end of follow-up, thus could in theory have predated the exposure. However, out of 56 occupationally exposed participants with incident COPD, most were already working at an exposed job at the start of follow-up or had a prebronchodilation FEV1/FVC > LLN at ECRHS II after having started working at exposed jobs. Only for $7 / 56$ participants (12.5\%) it could not be disproven that COPD might have occurred before the occupational exposure. Still this is very unlikely, as COPD incidence is strongly related to age and because participants developing COPD might be less likely to start working in exposed jobs unless previously exposed.

Nevertheless, the fact that some occupational exposure effects (namely biological dust, gases and fumes and pesticides) were observed even in this relatively young study population is highly important from a public health point of view. A large proportion of workers have these exposures (49\% among ever smokers in our study population), and their association with COPD incidence translates into a substantial number of attributable cases in the population (an estimated $21.0 \%$ in this analysis); this suggests that up to one in five new COPD cases among middle-aged people in Western countries could be prevented by avoiding or controlling occupational exposures in contemporary jobs. Our study confirms previous findings regarding the role of occupation on the burden of $\mathrm{COPD}^{68}$ and provides strong prospective evidence and direct quantitative estimates for the impact of occupational exposures on COPD incidence. Future studies should clarify whether these effects are modified by smoking, their interplay with asthma, and further detail the risks involved with respect to particular occupations, activities and noxious agents.

\section{Author affiliations}

'Barcelona Institute of Global Health (ISGlobal), Barcelona, Spain ${ }^{2}$ Universitat Pompeu Fabra (UPF), Barcelona, Spain

${ }^{3}$ CIBER Epidemiología y Salud Pública (CIBERESP), Madrid, Spain

${ }^{4}$ Hospital del Mar Medical Research Institute (IMIM), Barcelona, Spain

${ }^{5}$ IRAS, University of Utrecht, Utrecht, The Netherlands

${ }^{6}$ Department of Epidemiology and Social Medicine (ESOC), Faculty of Medicine and

Health Sciences, University of Antwerp, Antwerp, Belgium

${ }^{7}$ StatUA Statistics Centre, University of Antwerp, Antwerp, Belgium

${ }^{8}$ Institute and Outpatient Clinic for Occupational, Social and Environmental Medicine,

University Hospital of Ludwig Maximilians University, Comprehensive Pneumology

Centre Munich, German Centre for Lung Research, Munich, Germany

${ }^{9}$ Pulmonology Department, Galdakao Hospital, Bizkaia, Spain

${ }^{10}$ Servicio de Neumología, Complejo Hospitalario Universitario, Albacete, Spain

${ }^{11}$ Facultad de Medicina Albacete, Universidad de Castilla-La Mancha, Ciudad Real, Spain

${ }^{12}$ Respiratory Department, Hospital Universitario San Agustín, Aviles, Spain

${ }^{13}$ Respiratory and Allergy Clinical Unit, Universitary Hospitalary Complex, Huelva, Spain

${ }^{14}$ Université de Bordeaux, Inserm, Bordeaux Population Health Research Center, team EPICENE, UMR 1219, Bordeaux, France

${ }^{15}$ Department of Pédiatrie, CHU de Grenoble Alpes, Grenoble, France

${ }^{16}$ Inserm, U1209, IAB, Team of Environmental Epidemiology Applied to Reproduction and Respiratory Health, Grenoble, France

${ }^{17}$ Université Grenoble Alpes, Grenoble, France

${ }^{18}$ University Hospital of Montpellier, Montpellier, France
} 
${ }^{19}$ Sorbonne Universités, Paris, France

${ }^{20}$ Inserm UMR 1152-Equipe Epidémiologie, Université Paris Diderot, Paris, France

${ }^{21}$ Department of Health Sciences, Experimental and Forensic Medicine - Unit of Biostatistics and Clinical Epidemiology, University of Pavia, Pavia, Italy

${ }^{22}$ Department of Respiratory Medicine and Sleep, Landspitali University Hospital, Reykjavik, Iceland

${ }^{23}$ Faculty of Medicine, University of Iceland, Reykjavik, Iceland

${ }^{24}$ Department of Occupational Medicine, Haukeland University Hospital, Bergen, Norway

${ }^{25}$ Centre for International Health, University of Bergen, Bergen, Norway

${ }^{26}$ Department of Occupational and Environmental Medicine, Sahlgrenska University Hospital, Gothenburg, Sweden

${ }^{27}$ Department of Public Health and Clinical Medicine, Occupational and Environmental Medicine, Umeå University, Umeå, Sweden

${ }^{28}$ Department of Medical Sciences, Uppsala University, Uppsala, Sweden

${ }^{29}$ Research and Evaluation Office, Boston Public Health Commission, Boston, Massachusetts, USA

${ }^{30}$ Department of Epidemiology and Public Health, Swiss Tropical and Public Health Institute, Basel, Switzerland

${ }^{31}$ University of Basel, Basel, Switzerland

${ }^{32}$ Monash Centre for Occupation and Environmental Health, School of Public Health and Preventive Medicine, Monash University, Melbourne, Australia

${ }^{33}$ Lung Clinic, Tartu University Hospital, Tartu, Estonia

${ }^{34}$ Section of Occupational and Environmental Medicine, Institute of Medicine, Sahlgrenska Academy, University of Gothenburg, Gothenburg, Sweden

${ }^{35}$ Department of Public Health, Section for Environment, Occupation and Health, Danish Ramazzini Center, Aarhus University, Aarhus, Denmark

${ }^{36}$ National Research Center for the Working Environment, Copenhagen, Denmark

${ }^{37}$ Unit of Occupational Medicine, University Hospital of Verona, Verona, Italy

${ }^{38}$ University of California San Francisco, San Francisco Veterans Affairs Medical

Center, San Francisco, California, USA

${ }^{39}$ Population Health and Occupational Disease, National Heart and Lung Institute, Imperial College London, London, UK

${ }^{40}$ MRC-PHE Centre for Environment and Health, Imperial College London, London, UK

Contributors Study idea and design: TL, MK, JPZ, HK, JMA, KT, DJ. Data collection: MK, HK, AEC, JMA, HB, JW, JH, DN, IU, JMMR, JAG, APV, CRS, IP, PD, BL, SV, TG, CRS, $M H, B F, D N, A J M, N P H, G B, R J, K T, T S, V S, J G A, D J$, JPZ. Data analysis: TL, MK, JPZ. Data interpretation: all authors. Initial manuscript draft: TL, MK, JPZ. Critical revision of the manuscript for important intellectual content: all authors. Final approval of the manuscript for publication: all authors.

Funding Financial support for ECRHS I, for the localcentres included in this study: Australia: Asthma Foundation of Victoria, Allenand Hanbury's, Belgium: Belgian Science Policy Office, National Fundfor Scientific Research, Estonia: Estonian Science Foundation, grantno 1088, France: Ministère de la Santé, Glaxo France, InsitutPneumologique d'Aquitaine, Contrat de Plan Etat-RégionLanguedocRousillon, CNMATS, CNMRT (90MR/10, 91AF/6), Ministredelegué de la santé, RNSP, France; GSF, Germany: Bundesminister für Forschung und Technologie, Italy: Ministero dell'Università edella Ricerca Scientifica e Tecnologica, CNR, Regione Veneto grantRSF n. 381/05.93, Norway: Norwegian Research Council project no.101422/310; Spain: Fondo de Investigación Sanitaria(\#91/0016-060-05/E, 92/0319 and \#93/0393), Hospital General deAlbacete, Hospital General Juan Ramón Jiménez, DirecciónRegional de Salud Pública (Consejería de Sanidad del Principado deAsturias), CIRIT (1997 SGR 00079) and Servicio Andaluz de Salud; Sweden: The Swedish Medical Research Council, the Swedish Heart LungFoundation, the Swedish Association against Asthma and Allergy; Switzerland: Swiss national Science Foundation grant 4026-28099; UK:National Asthma Campaign, British Lung Foundation, Department ofHealth, South Thames Regional Health Authority. Financial Support for ECRHS III: Australia: National Health \& Medical ResearchCouncil, Belgium: Antwerp South, Antwerp City: Research FoundationFlanders (FWO), grant code G.0.410.08.N.10 (both sites), Estonia:Tartu- SF0180060s09 from the Estonian Ministry of Education. France:(All) Ministère de la Santé. Programme Hospitalier de RechercheClinique (PHRC) national 2010. Bordeaux: INSERM U897 UniversitéBordeaux segalen, Grenoble: Comite Scientifique AGIRadom 2011. Paris:Agence Nationale de la Santé, Région lle de France, domained'intérêt majeur (DIM) Germany : Erfurt: German ResearchFoundation HE 3294/10-1 Hamburg: German Research Foundation MA711/6-1, NO 262/7-1 Iceland: Reykjavik, The Landspitali UniversityHospital Research Fund, University of Iceland Research Fund, ResMedFoundation, California, USA, Orkuveita Reykjavikur (Geothermalplant), Vegagerðin (The Icelandic Road Administration (ICERA). Italy: All Italian centres were funded by the Italian Ministry ofHealth, Chiesi Farmaceutici SpA, in addition Verona was funded byCariverona foundation, Education Ministry (MIUR). Norway: NorwegianResearch council grant no 214123, Western Norway Regional HealthAuthorities grant no 911631, Bergen Medical Research Foundation. Spain: Fondo de Investigación Sanitaria (PS09/02457, PS09/0071609/01511) PS09/02185 PS09/03190), Servicio Andaluz de Salud, SociedadEspañola de
Neumología y Cirurgía Torácica (SEPAR 1001/2010);Sweden: All centres were funded by The Swedish Heart and LungFoundation, The Swedish Asthma and Allergy Association, The SwedishAssociation against Lung and Heart Disease. Fondo de InvestigaciónSanitaria (PS09/02457 Barcelona: Fondo de Investigación Sanitaria(FIS PS09/00716) Galdakao: Fondo de Investigación Sanitaria (FIS09/01511) Huelva: Fondo de Investigación Sanitaria (FIS PS09/02185)and Servicio Andaluz de Salud Oviedo: Fondo de InvestigaciónSanitaria (FIS PS09/03190) Sweden: All centres were funded by TheSwedish Heart and Lung Foundation, The Swedish Asthma and AllergyAssociation, The Swedish Association against Lung and Heart Disease. Swedish Research Council for health, working life and welfare (FORTE)Göteborg :Also received further funding from the Swedish Council for Working life and Social Research. Umea also received funding fromVasterbotten Country Council ALF grant. Switzerland: The SwissNational Science Foundation (grants no 33CSCO134276/1,33CSCO-108796, 3247BO-104283, 3247BO-104288, 3247BO104284,3247-065896, 3100-059302, 3200-052720, 3200-042532, 4026-028099) TheFederal office for forest, environment and landscape, The FederalOffice of Public Health, The Federal Office of Roads and Transport, the canton's government of Aargan, Basel-Stadt, Basel-Land, Geneva,Luzern, Ticino, Valais and Zürich, the Swiss Lung League, thecanton's Lung League of Basel Stadt/ Basel, Landschaft, Geneva, Ticino, Valais and Zurich, SUVA, Freiwillige AkademischeGesellschaft, UBS Wealth Foundation, Talecris Biotherapeutics $\mathrm{GmbH}$,Abbott Diagnostics, European Commission 018996 (GABRIEL), WellcomeTrust WT 084703MA, UK: Medical Research Council (Grant Number 92091).Support also provided by the National Institute for Health Researchthrough the Primary Care Research Network The coordination of the ECRHS III was fundedthrough the Medical Research Council (Grant Number 92091). ISGlobal is a member of the CERCA Programme /Generalitat de Catalunya. The present analyses are part of the Ageing Lungsin European Cohorts (ALEC) Study (www.alecstudy.org), which hasreceived funding from the European Union's Horizon 2020 research andinnovation programme under grant agreement No. 633212

Competing interests None declared.

Ethics approval Local committees for each study centre.

Provenance and peer review Not commissioned; externally peer reviewed.

(c) Article author(s) (or their employer(s) unless otherwise stated in the text of the article) 2018. All rights reserved. No commercial use is permitted unless otherwise expressly granted.

\section{REFERENCES}

1 Global Initiative for Chronic Obstructive Lung Disease (GOLD). Global strategy for the diagnosis, management, and prevention of chronic obstructive pulmonary disease, 2017 report. 2017

2 Lozano R, Naghavi M, Foreman K, et al. Global and regional mortality from 235 causes of death for 20 age groups in 1990 and 2010: a systematic analysis for the Global Burden of Disease Study 2010. Lancet 2012;380:2095-128.

3 Prince MJ, Wu F, Guo Y, et al. The burden of disease in older people and implications for health policy and practice. Lancet 2015;385:549-62

4 Herse F, Kiljander T, Lehtimäki L. Annual costs of chronic obstructive pulmonary disease in Finland during 1996-2006 and a prediction model for 2007-2030. NPJ Prim Care Respir Med 2015:25:15015.

5 Kohansal R, Martinez-Camblor P, Agustí A, et al. The natural history of chronic airflow obstruction revisited: an analysis of the Framingham offspring cohort. Am J Respir Crit Care Med 2009;180:3-10

6 Eisner MD, Anthonisen N, Coultas D, et al. An official American Thoracic Society public policy statement: novel risk factors and the global burden of chronic obstructive pulmonary disease. Am J Respir Crit Care Med 2010;182:693-718.

7 Paulin LM, Diette GB, Blanc PD, et al. Occupational exposures are associated with worse morbidity in patients with chronic obstructive pulmonary disease. Am J Respir Crit Care Med 2015;191:557-65.

8 Balmes J, Becklake M, Blanc P, et al. American Thoracic Society statement: occupational contribution to the burden of airway disease. Am J Respir Crit Care Med 2003;167:787-97.

9 Omland O, Würtz ET, Aasen TB, et al. Occupational chronic obstructive pulmonary disease: a systematic literature review. Scand J Work Environ Health 2014;40:19-35.

10 Krzyzanowski M, Jedrychowski W, Wysocki M. Factors associated with the change in ventilatory function and the development of chronic obstructive pulmonary disease in a 13-year follow-up of the Cracow Study. Risk of chronic obstructive pulmonary disease. Am Rev Respir Dis 1986;134:1011-9.

11 Seixas NS, Robins TG, Attfield MD, et al. Exposure-response relationships for coal mine dust and obstructive lung disease following enactment of the Federal Coal Mine Health and Safety Act of 1969. Am J Ind Med 1992:21:715-34

12 Blanc PD, Iribarren C, Trupin L, et al. Occupational exposures and the risk of COPD: dusty trades revisited. Thorax 2009;64:6-12.

13 Hnizdo E, Sullivan PA, Bang KM, et al. Association between chronic obstructive pulmonary disease and employment by industry and occupation in the US population: 
a study of data from the Third National Health and Nutrition Examination Survey. Am J Epidemiol 2002;156:738-46.

14 Salvi SS, Barnes PJ. Chronic obstructive pulmonary disease in non-smokers. Lancet 2009:374:733-43.

15 Terzikhan N, Verhamme KM, Hofman A, et al. Prevalence and incidence of COPD in smokers and non-smokers: the Rotterdam Study. Eur J Epidemiol 2016;31:785-92.

16 Afonso AS, Verhamme KM, Sturkenboom MC, et al. COPD in the general population: prevalence, incidence and survival. Respir Med 2011:105:1872-84.

17 Mehta AJ, Miedinger D, Keidel D, et al. Occupational exposure to dusts, gases, and fumes and incidence of chronic obstructive pulmonary disease in the Swiss cohort study on air pollution and lung and heart diseases in adults. Am J Respir Crit Care Med 2012;185:1292-300.

18 Kauffmann F, Drouet D, Lellouch J, et al. Occupational exposure and 12-year spirometric changes among Paris area workers. Br I Ind Med 1982;39:221-32.

19 Heederik D, Kromhout H, Kromhout D, et al. Relations between occupation, smoking, lung function, and incidence and mortality of chronic non-specific lung disease: the Zutphen Study. Br J Ind Med 1992:49:299-308.

$20 \mathrm{Ng} \mathrm{M}$, Freeman MK, Fleming TD, et al. Smoking prevalence and cigarette consumption in 187 countries, 1980-2012. JAMA 2014:311:183-92.

21 Syamlal G, Mazurek JM, Hendricks SA, et al. Cigarette smoking trends among U.S. working adult by industry and occupation: findings from the 2004-2012 National Health Interview Survey. Nicotine Tob Res 2015;17:599-606.

22 Zock JP, Sunyer J, Kogevinas M, et al. Occupation, chronic bronchitis, and lung function in young adults. An international study. Am J Respir Crit Care Med 2001;163:1572-7

23 Sunyer J, Zock JP, Kromhout H, et al. Lung function decline, chronic bronchitis, and occupational exposures in young adults. Am J Respir Crit Care Med 2005:172:1139-45.

24 Burney PG, Luczynska C, Chinn S, et al. The European Community Respiratory Health Survey. Eur Respir J 1994;7:954-60.

25 Quanjer PH, Stanojevic S, Cole TJ, et al. Multi-ethnic reference values for spirometry for the 3-95-yr age range: the global lung function 2012 equations. Eur Respir J 2012:40:1324-43.

26 Matheson MC, Benke G, Raven J, et al. Biological dust exposure in the workplace is a risk factor for chronic obstructive pulmonary disease. Thorax 2005;60:645-51.

27 de Marco R, Accordini S, Cerveri I, et al. Incidence of chronic obstructive pulmonary disease in a cohort of young adults according to the presence of chronic cough and phlegm. Am J Respir Crit Care Med 2007;175:32-9.

28 Svanes $C$, Sunyer J, Plana E, et al. Early life origins of chronic obstructive pulmonary disease. Thorax 2010;65:14-20.
29 Castaldi PJ, Demeo DL, Hersh CP, et al. Impact of non-linear smoking effects on the identification of gene-by-smoking interactions in COPD genetics studies. Thorax 2011;66:903-9.

30 Plummer M. JAGS: a program for analysis of Bayesian graphical models using gibbs sampling. Vienna, 2003:125.

31 Rockhill B, Newman B, Weinberg C. Use and misuse of population attributable fractions. Am J Public Health 1998;88:15-19.

32 R Core Team. R: a language and environment for statistical computing. Vienna, Austria: R Foundation for Statistical Computing, 2015.

33 Christiani DC, Wang XR, Pan LD, et al. Longitudinal changes in pulmonary function and respiratory symptoms in cotton textile workers. A 15-yr follow-up study. Am J Respir Crit Care Med 2001;163:847-53.

34 Jacobsen GH, Schlünssen V, Schaumburg I, et al. Cross-shift and longitudinal changes in FEV1 among wood dust exposed workers. Occup Environ Med 2013;70:22-8.

35 Kahraman H, Sucakli MH, Kilic T, et al. Longitudinal pulmonary functional loss in cotton textile workers: a 5-year follow-up study. Med Sci Monit 2013;19:1176-82.

36 Mandryk J, Alwis KU, Hocking AD. Work-related symptoms and dose-response relationships for personal exposures and pulmonary function among woodworkers. Am J Ind Med 1999:35:481-90.

37 Alif SM, Dharmage SC, Benke G, et al. Occupational exposure to pesticides are associated with fixed aifflow obstruction in middle-age. Thorax 2017;72:990-7.

38 Doust E, Ayres JG, Devereux G, et al. Is pesticide exposure a cause of obstructive airways disease? Eur Respir Rev 2014;23:180-92.

39 Negatu B, Kromhout H, Mekonnen Y, et al. Occupational pesticide exposure and respiratory health: a large-scale cross-sectional study in three commercial farming systems in Ethiopia. Thorax 2017:72:498.1-9.

40 de Jong K, Boezen HM, Kromhout H, et al. Association of occupational pesticide exposure with accelerated longitudinal decline in lung function. Am J Epidemiol 2014;179:1323-30

41 Kogevinas M, Zock JP, Jarvis D, et al. Exposure to substances in the workplace and new-onset asthma: an international prospective population-based study (ECRHS-II) Lancet 2007;370:336-41.

42 Postma DS, Rabe KF. The asthma-COPD overlap syndrome. N Engl J Med 2015;373:1241-9.

43 Pallasaho P, Kainu A, Sovijärvi A, et al. Combined effect of smoking and occupational exposure to dusts, gases or fumes on the incidence of COPD. COPD 2014;11:88-95.

44 Lindberg A, Jonsson AC, Rönmark E, et al. Ten-year cumulative incidence of COPD and risk factors for incident disease in a symptomatic cohort. Chest 2005;127:1544-52. 